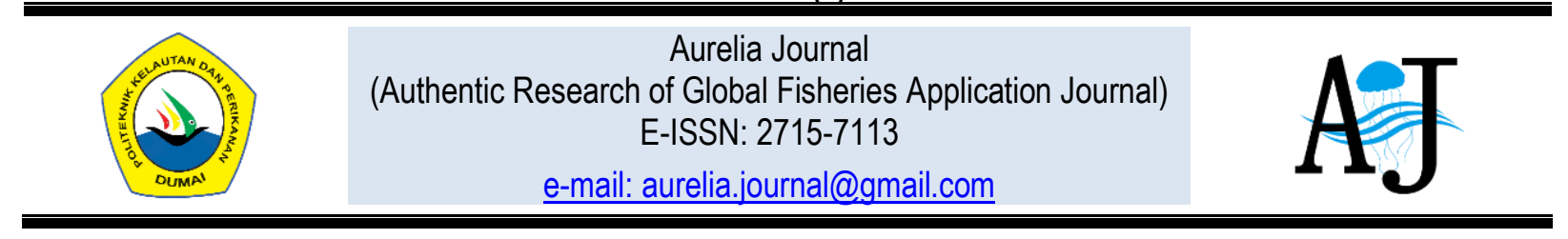

\title{
PENGOPERASIAN DAN PERAWATAN SISTEM PENDINGIN PADA MESIN INDUK KAPAL KM. SIDO MULYO SANTOSO DI PPN SIBOLGA
}

\section{OPERATION AND MAINTENANCE OF COOLING SYSTEM ON MAIN ENGINE KM. SIDO MULYO SANTOSO AT PPN SIBOLGA}

\author{
Boby Wisely Ziliwu1 ${ }^{*}$, Iskandar Musa1, Yuniar Endri Priharanto ${ }^{1}$, Tono1 \\ 1Politeknik Kelautan dan Perikanan Dumai, Jl. Wan Amir, No.1, Kelurahan Pangkalan Sesai, \\ Kecamatan Dumai Barat, Kota Dumai, Provinsi Riau, Indonesia \\ *Korespondensi: bobyziliwu@gmail.com (BW Ziliwu) \\ Diterima 19 Januari 2021 - Disetujui 16 Februari 2021
}

\begin{abstract}
ABSTRAK. Sistem pendingin dilengkapi dalam mesin untuk pendingin dan mencegah terjadinya panas yang berlebihan, sistem pendingin disamping bertujuan untuk mencegah keadaan tersebut, diperlukan untuk mengatur dan mempertahankan suhu temperatur yang tetap dalam mesin beroperasi dengan cara mengalirkan media pendingin untuk bagian-bagian mesin yang hendak didinginkan, sistem pendingin juga harus diperhatikan agar mesin dapat beroperasi dengan baik, salah satu komponen sistem pendingin adalah alat penukar kalor (heat exchanger) mempunyai peranan yang sangat penting dalam menunjang kinerja sistem pendingin. Heat exchanger adalah suatu alat yang dimana terjadi aliran perpindahan panas diantara dua fluida atau lebih pada temperatur yang berbeda. Penelitian ini dilaksanakan di atas kapal KM. Sido Mulyo Santoso di Pelabuhan Perikanan Nusantara Sibolga. Sistem pendingin yang digunakan pada kapal KM. Sido Mulyo Santoso yaitu sistem pendingin tidak langsung, dimana sistem tidak langsung ini air laut dihisap menggunakan pompa sentrifugal kemudian air laut tersebut kemudian dihisap oleh pompa air tawar untuk dialirkan ke komponen mesin induk. Tujuan dari penelitian ini untuk mengetahui bagaimana melakukan perawatan dan pengoperasian sistem pendingin pada mesin induk yang ada di atas kapal KM. Sido Mulyo Santoso. Perawatan yang dilakukan ada 2 cara kerja, yaitu perawatan bulanan dan perawatan tak terduga.
\end{abstract}

KATA KUNCI: Sistem pendingin, Alat Penukar Panas, Mesin Induk, Perawatan

ABSTRACT. The cooling system is equipped in the engine for cooling and preventing excessive heat, the cooling system in addition to preventing this situation, is needed to regulate and maintain a constant temperature in the engine operating by flowing the cooling medium for the engine parts to be cooled, Cooling must also be considered so that the engine can operate properly, one component of the cooling system is a heat exchanger which has a very important role in supporting the performance of the cooling system. Heat exchanger is a device in which the flow of heat transfer occurs between two or more fluids at different temperatures. This research was conducted on board the KM. Sido Mulyo Santoso at Nusantara Fishing Por Sibolga t. The cooling system used on KM ships. Sido Mulyo Santoso is an indirect cooling system, where this indirect system of seawater is sucked using a centrifugal pump, then the sea water is then sucked by a fresh water pump to flow to the main engine components. The purpose of this study was to determine how to maintain and operate the cooling system on the main engine onboard the KM ship. Sido Mulyo Santoso. There are 2 ways to do the treatment, namely monthly maintenance and unexpected maintenance

KEYWORDS: Cooling system, Heat Exchanger, Main Engine, Maintenance

\section{Pendahuluan}

Dunia permesinan sangatlah membutuhkan suatu sistem pendingin (Legiman \& Sulaiman, 2014), seperti torak (piston) kepala silinder/katup/dinding silinder akan menyerap sejumlah panas yang sangat besar, saat suhu bagian-bagian mesin bertambah panas, lapisan minyak pelumas yang 
akan memisahkan bagian mesin yang saling bergesekan menjadi pecah, bila ini terjadi sistem pelumasan tidak berfungsi lagi dan mesin akan rusak, panas yang diserap mesin harus sesegera mungkin dibuang, sebab bila tidak mesin akan terlalu panas dan mempercepat keausan dan kerusakan pada mesin (Darma et al., 2010). Maka sistem pendingin dilengkapi dalam mesin untuk pendingin dan mencegah panas yang berlebihan, sistem pendingin di samping bertujuan untuk mencegah keadaan tersebut, diperlukan untuk mengatur dan mempertahankan suhu temperatur yang tetap dalam dalam mesin beroperasi dengan cara mengalirkan media pendingin untuk bagian- bagian mesin yang hendak didinginkan. Sistem pendingin juga harus diperhatikan agar mesin dapat beroperasi dengan baik salah satu komponen sistem pendingin yaitu adalah alat penukar kalor (heat exchanger) mempunyai peranan yang sangat penting dalam menunjang kinerja sistem pendingin. Unit penukar kalor adalah suatu alat untuk memindahkan panas dari suatu fluida ke fluida lain. Salah satu tipe alat penukar kalor yang banyak dipakai oleh shell and tube (heat exchanger), alat ini terdiri dari sebuah shell silindris di bagian luar dan sejumlah tube di bagian dalam. Dimana temperatur fluida di dalam tube berbeda dengan di luar tube (di dalam shell) sehingga terjadi perpindahan panas antara aliran fluida di dalam tube dan di luar tube. Adapun daerah yang berhubungan dengan bagian dalam tube disebut dengan tube side dan yang di luar dari tube disebut shell side.

Sistem pendingin merupakan sistem yang berfungsi menjaga temperatur mesin pada suhu tertentu sesuai dengan disain yang ditentukan agar mesin diesel dapat beroperasi secara berkelanjutan. Mesin diesel yang beroperasi menghasilkan panas dengan suhu tinggi, sistem pendingin ini terdiri dari beberapa komponen penyusun yang utamanya untuk mendinginkan blok mesin, selain mendinginkan blok mesin sistem pendingin juga mendinginkan pelumas, scavange air dan water jacket (Julianto et al., 2016). Untuk pendinginan dari sebuah mesin diesel diperlukan suatu sistem yang terdiri dari pipa, pompa dan pendingin atau cooler, yang berfungsi untuk menurunkan suhu suatu cairan atau udara dari suhu tinggi kesuhu yang lebih rendah dengan bantuan bahan pendingin yaitu air atau udara. Panas akibat pembakaran yang berlebihan mengakibatkan komponen mesin mengalami kenaikan temperatur yang berlebihan (over heating) komponen-komponen seperti torak dan dinding silinder menjadi macet, dan kepala silinder akan mejadi retak, untuk mengatasi masalah tersebut maka diperlukan sistem pendingin (Legiman \& Sulaiman, 2014)Fungsi sistem pendingin adalah sebagai berikut :

1. 1.Mengurangi panas yang dihasilkan oleh pembakaran campuran bahan bakar dengan udara yang dapat mencapai temperatur $2500^{\circ} \mathrm{C}$, panas yang cukup tinggi ini dapat melelehkan logam dan komponen lain yang dapat mengganggu kinerja sistem pendingin.

2. Mempertahankan temperatur mesin agar selalu pada temperatur kerja yang optimal.

3. Mempercepat pencapaian temperatur kerjanya mesin, karena untuk mencegah terjadinya keausan dan emisi gas buang yang berlebihan.

Heat exchanger merupakan sebuah mesin terjadinya aliran perpindahan panas diantara dua fluida atau lebih pada temperatur yang berbeda (Sudrajat, 2017), dimana fluida tersebut keduanya mengalir di dalam sistem. Di dalam heat exchanger tersebut, kedua fluida yang mengalir terpisah satu sama lain, biasanya oleh pipa silindris. Fluida dengan temperatur yang lebih tinggi akan mengalirkan panas ke fluida yang temperatur yang lebih rendah. Shell and tube merupakan jenis heat exchanger yang populer dan lebih banyak digunakan. Shell and tube terdiri dari sejumlah tube yang terpasang di dalam shell yang berbentuk silindris, dimana satu fluida mengalir di dalam tube, dan yang lainnya mengalir di luar tube.

Pengoperasian sistem pendingin pada mesin induk di kapal dilakukan selama 24 jam selama 1 minggu hingga 1 bulan salam pelayaran. Kondisi ini perlu diperhatikan agar mesin secara terus menerus tidak mengalami penurunan kinerja yang mengakibatkan kegagalan. Perhatian khusus pada mesin saat pelayaran maupun setelah pelayaran merupakan perhatian khusus. Perawatan sistem pendingin merupakan langkah awal untuk mencegah kegagalan yang akan terjadi secara dini (Yaqin, Zamri, et al., 2020; Yaqin, Ziliwu, et al., 2020). Perawatan dilakukan setelah pengoperasian dilakukan maupun saat sistem pendingin mesin induk berjalan. Adapun tujuan dari penelitian ini adalah 
mengetahui bagaimana prinsip kerja sistem pendingin (heat exchanger), mengetahui dan memahami fungsi dari komponen-komponen system pendingin (heat exchanger), dan mengetahui bagaimana cara perawatan pada sistem pendingin (heat exchanger).

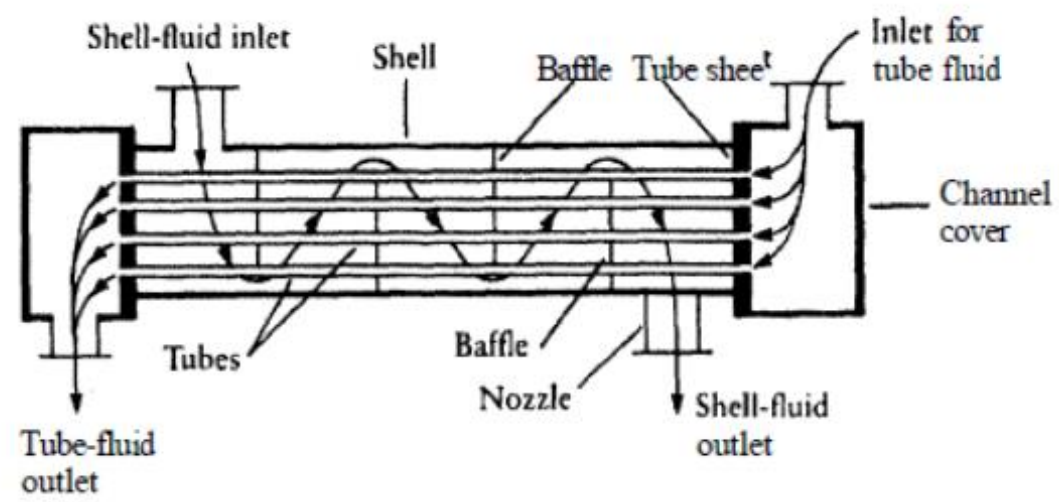

(Sumber : Budiman et al., 2014)

Gambar 1 Kontruksi Heat Exchanger

\section{Metode}

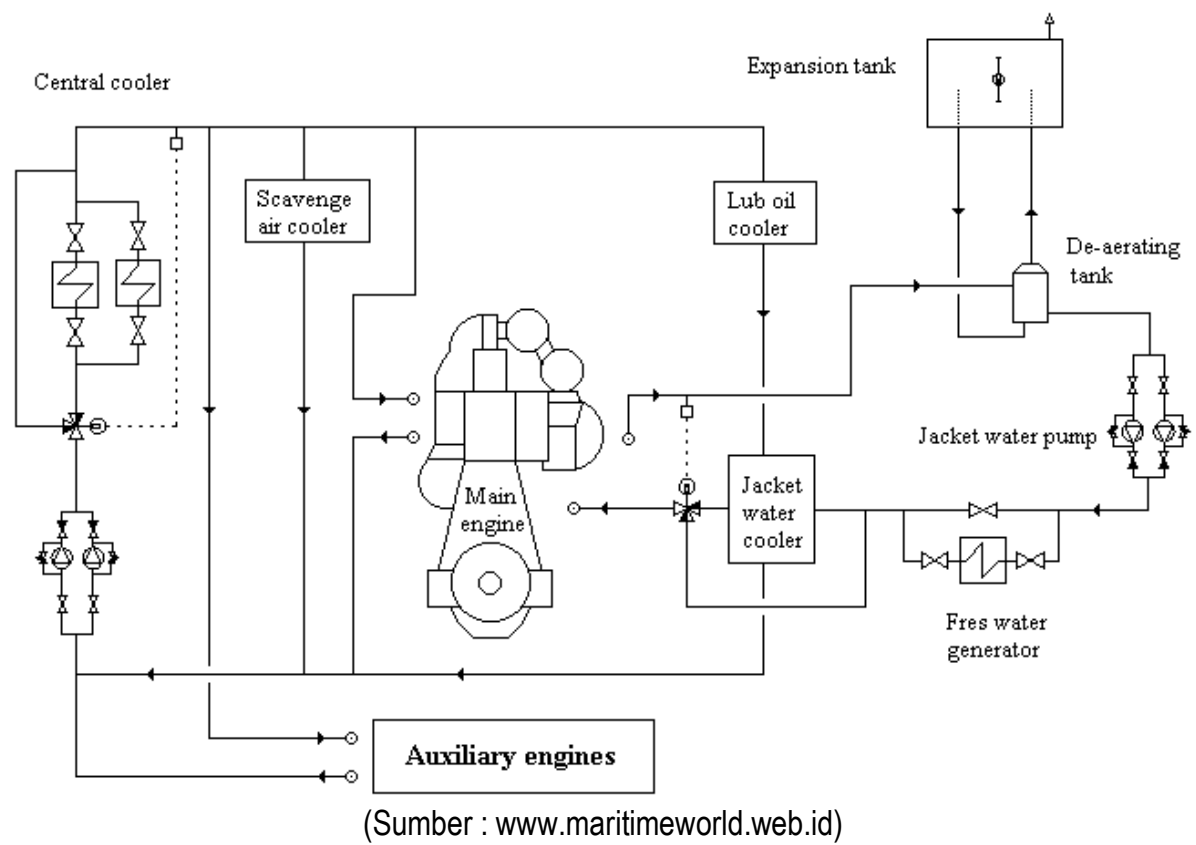

Gambar 2. Skema Sistem Pendingin

Pelaksanaan penelitian ini dilakukan mulai tanggal 15 maret 2020 hingga 20 Juni 2020 kurang lebih selama 4 bulan di atas kapal KM. Sido Mulyo Santoso. Analisis data yang diperoleh dengan mengamati cara kerja sistem pendingin (heat exchanger) yang merupakan pendataan secara langsung keluar masuk air laut. Metode penelitian yang digunakan yaitu $\mathrm{m}$ etode survey. Metode survei adalah $\mathrm{m}$ etode pengam atan atau observasi secara langsung dilapangan. Penulis secara langsung $\mathrm{m}$ engam ati cara kerja sistem pendingin (heat exchange).

Metode yang penulis lakukan untuk $\mathrm{m}$ engolah data yang akan menjadi topik judul kerja praktik akhir (KPA) adalah sebagai berikut:

a. Pendekatan secara deskriptif

Metode deskriptif yaitu metode dengan mengkaji pengam atan cara kerja sistem pendingin mesin induk (heat exchanger) pada kapal KM. Sido Mulyo Santoso dengan membandingkan dengan teori yang ada. 
b. Pendekatan secara kuantitatif

Metode Kuntitatif yaitu dengan $\mathrm{m}$ encari sum ber dari data jurnal yang $\mathrm{m}$ em bahas tentang sistem pendingin (heat exchanger).

\section{Hasil dan Pembahasan}

KM. Sido Mulyo Santoso adalah sebuah kapal penangkap ikan dan juga menjadi salah satu sarana bagi penulis dalam melakukan penelitian. Kapal ini menggunakan alat tangkap jenis purse seine, yang target hasil tangkapan utamanya adalah ikan cakalang, tongkol, dan beberapa jenis ikan lainya. Daerah penangkapan kapal ini atau fishing ground nya adalah daerah sekitaran perairan Samudra Hindia. Berikut ini gambar kapal KM. Sido Mulyo Santoso.

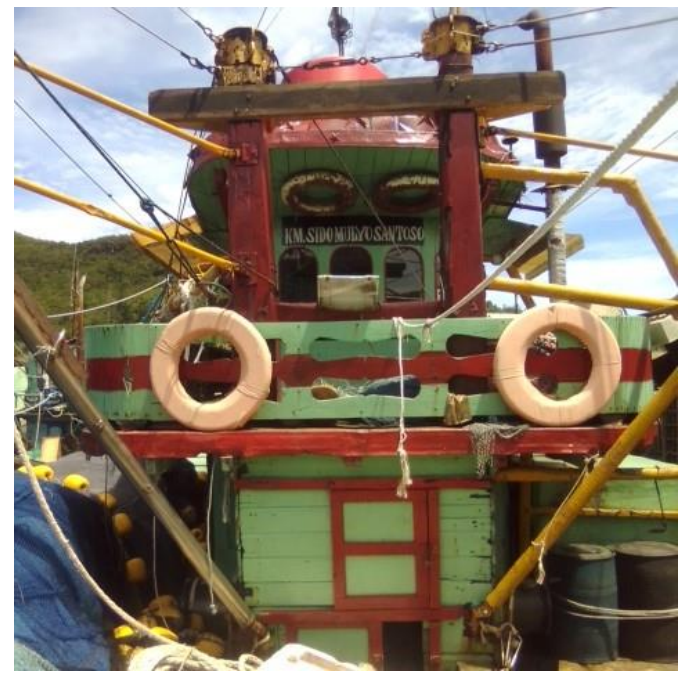

Gambar 3. KM. Sido Mulyo Santoso

Dibawah ini merupakan spesifikasi data KM. Sido Mulyo Santoso sebagai berikut:

Tabel 1. Spesifikasi Data Kapal KM. Sido Mulyo Santoso

\begin{tabular}{ll}
\multicolumn{1}{c}{ Keterangan } & \multicolumn{1}{c}{ Spesifikasi } \\
\hline Nama Kapal & KM. Sido Mulyo Santoso \\
Tempat \& No Grose Akte & Semarang/1703 \\
Tempat \& No Buku Kapal & Jakarta/006458 \\
Tanda Selar & Cirebon/GT.98 No. 1929 Da \\
Tanda Pengenal Kapal & A/572/573/kp-ps 006458 \\
Call Sign & - \\
Tahun Pembuatan Kapal & 1995 \\
Tempat Pembuatan Kapal & Pekalongan \\
Berat Kotor & $98 \mathrm{GT}$ \\
Berat Bersih & $30 \mathrm{GT}$ \\
Merek Mesin & Nissan \\
No Seri Mesin & 107100 \\
\hline
\end{tabular}

Generator merupakan salah satu pesawat bantu yg sangat penting diatas kapal, Generator berfungsi sebagai pembangkit listrik diatas kapal serta menghidupkan pompa-pompa supaya beroperasi. Generator yang digunakan diatas kapal KM. Sido Mulyo Santoso adalah sebagai berikut. Gambar 4 dan Tabel 2 menunjukkan data dari Generator yang digunakan pada KM. Sido Mulyo Santoso. 


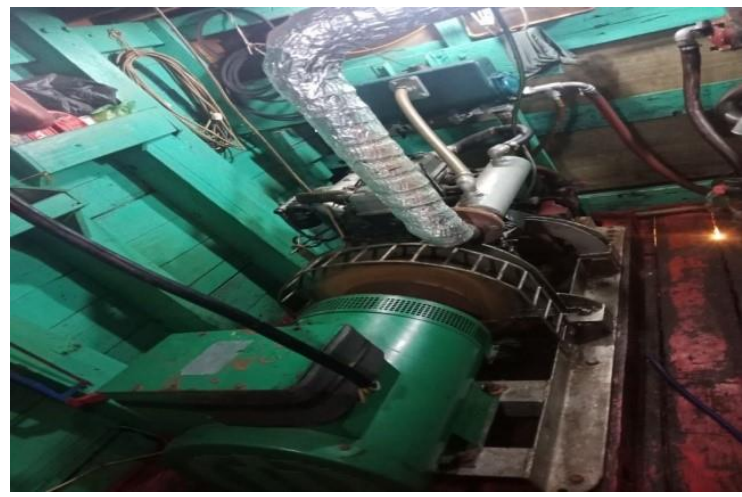

Gambar 4. Generator KM. Sido Mulyo Santoso

Tabel 2. Spesifikasi Data Generator KM. Sido Mulyo Santoso

\begin{tabular}{lll} 
& Spesifikasi & Nilai \\
\hline Jenis Generator & AC \\
Daya & $50 \mathrm{kVa}$ \\
Phase & 3 \\
Frekuensi & $50 \mathrm{~Hz}$ \\
Tegangan & $380 \mathrm{~V}$ \\
\hline
\end{tabular}

Sistem pendingin adalah suatu komponen pada mesin yang berfungsi untuk mengatasi terjadinya over heating (panas yang berlebihan) sehingga mesin bisa bekerja dengan stabil. Adapun sistem pendingin (heat exchanger) yang digunakan Pada kapal KM. Sido Mulyo Santoso menggunakan sistem pendingin tidak langsung. Berikut komponen-komponen sistem pendingin pada KM. Sido Mulyo Santoso :

a. Pompa Sentrifugal Pompa Sentrifugal adalah komponen pada sistem pendingin yang berfungsi sebagai penghisap air laut yang kemudian dialirkan ke dalam Water cooler, sehingga air tawar didinginkan oleh air laut. Berikut perawatan pompa Sentrifugal pada sistem pendingin diatas kapal KM. Sido Mulyo Santoso:

1. Belting (tali pulley)

Biasanya belting diganti setelah putus, terkadang dilihat dari kondisi belting apakah masih layak dipakai atau masih bisa digunakan, terkadang Belting diganti ketika kapal KM. Sido Mulyo Santoso berlayar selama 2 bulan atau 4 trip melakukan penangkapan.

2. Oil Seal

Oli seal diganti kisaran dua bulan sampai tiga bulan operasi, jika tidak maka akan terjadi kebocoran oli kemudian masuk ke dalam kipas pompa sentrifugal dan menghambat kerja pompa sentrifugal.

3. Nok

Nok berfungsi untuk menutup putaran kipas agar tidak masuk air, apabila nok rusak maka air akan masuk kedalam kipas dan memperhambat kerja pompa Sentrifugal, di kapal KM. Sido Mulyo santoso biasanya nok diganti kisaran satu sampai dua bulan.

4. Bearing

Bearing berfungsi untuk memutarkan as pulley (belting), apabila Bearing rusak (pecah) maka pompa Sentrifugal tidak bias berfungsi. Biasanya Bearing diganti kisaran tiga bulan sampai empat bulan operasi 


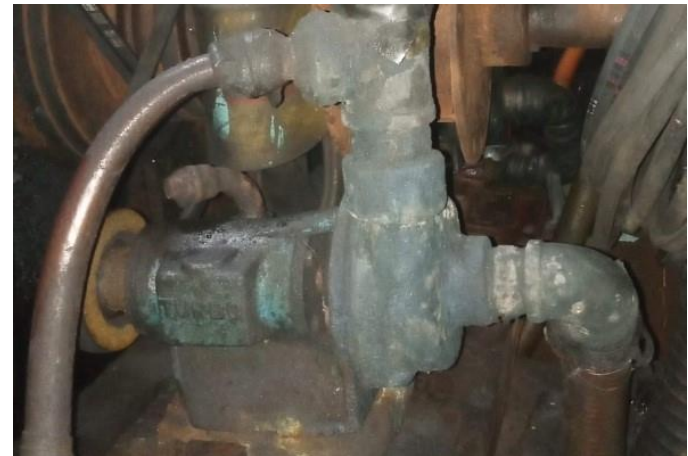

Gambar 5 Pompa Sentrifugal

b. Pompa Air Tawar

Pompa air tawar berfungsi untuk menghisap air tawar yang ada di dalam water cooler (bowman) yang sudah didinginkan oleh air laut, kemudian air tawar tersebut dialirkan ke dalam komponen mesin induk yang akan didinginkan. Berikut perawatan pompa air tawar diatas kapal KM. Sido Mulyo Santoso.

1. Belting (tali pulley)

Belting diganti setelah dua bulan layar atau melakukan kegiatan penangkapan sebanyak empat trip.

2. Oil Seal

Oli seal diganti kisaran dua bulan sampai tiga bulan layar atau melakukan kegiatan penangkapan sebanyak lima sampai enam trip.

3. Nok

Nok diganti kisaran satu bulan sampai dua bulan operasi.

4. Bearing

Bearing biasanya diganti setelah tiga bulan sampai empat bulan operasi.

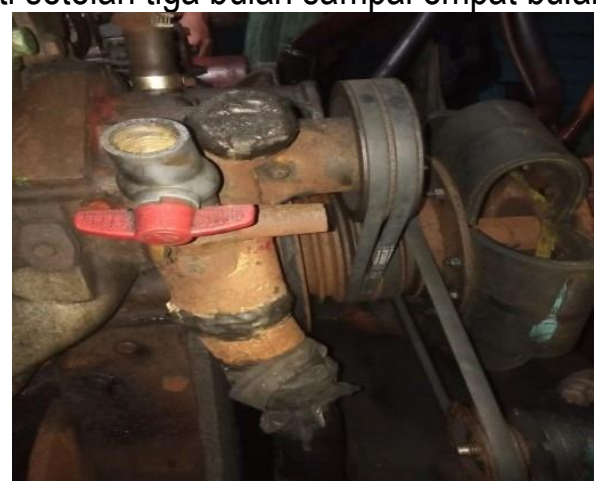

Gambar 6. Pompa Air Tawar

c. Kran Utama

Kran berfungsi untuk mengontrol atau buka tutup pintu masuk air laut kedalam sistem pendingin, apabila kran mengalami kendala maka akan jadi penghambat dalam pengoperasian sistem pendingin. Berikut perawatan kran pada sistem pendingin diatas kapal KM. Sido Mulyo Santoso :

1. Apabila kran terlalu ketat maka dikasi oli ataupun pelumas supaya kran bisa berfungsi dengan baik dan memudahkan dalam menutup dan membuka pintu air laut.

2. Apabila kran pada sistem pendingin mengalami retak ataupun bengkok yang diakibatkan oleh benda lain (tidak layak pakai) maka segera diganti dengan yang baru supaya mempermudah dalam pengoperasian.

d. Selang

Selang berfungsi sebagai sarana atau tempat mengalirnya bahan pendingin dari satu komponen ke komponen yg lainnya, apabila selang mengalami kendala maka sistem pendingin akan 
terhambat bahkan tidak bisa berfungsi. Berikut perawatan selang pada sistem pendingin diatas kapal KM. Sido Mulyo santoso:

1. Apabila selang mengalami penyumbatan akibat sampah yang ikut tersedot oleh air laut maka selang harus segera dibersihkan dan di buang sampah tersebut, jika tidak di buang maka selang akan tersumbat dan memperkecil ruang untuk air laut masuk.

2. Apabila selang mengalami goresan akibat benda kerja tajam maka harus diganti, jika tidak diganti lama kelamaan akan mengalami kebocoran dan jadi penghambat sistem pendingin.

e. Water Cooler

Water cooler adalah suatu wadah atau tempat bersirkulasinya air laut yang akan mendinginkan air tawar yang berada didalamnya. Berikut perawatan water cooler yang ada di kapal KM. Sido Mulyo Santoso. Membersihkan sel-sel atau tempat bersirkulasinya air laut, jika tidak dibersihkan maka sel-sel tersebut akan tersumbat dan akan mengurangi jumlah air laut yg bersirkulasi dan menyebabkan pendinginan kurang maksimal.

Prinsip kerja sistem pendingin pada kapal KM. Sido Mulyo Santoso yaitu menggunakan sistem pendingin tidak langsung, dimana air laut dihisap oleh pompa sentrifugal yang kemudian air laut tersebut dialirkan kedalam komponen water cooler, yang mana didalam komponen cooler tersebut terdapat air tawar, kemudian air tawar tersebut didinginkan oleh air laut, setelah air tawar didinginkan kemudian dialirkan kedalam komponen-komponen mesin induk yang yang akan didinginkan, seperti torak (piston), kepala silinder, katup, dan dinding silinder, serta komponen blok silinder lainnya (Djeli \& Saidah, 2016).

\section{Tabel 3. Perawatan Komponen Sistem Pendingin Pada KM. Sido Mulyo Santoso}

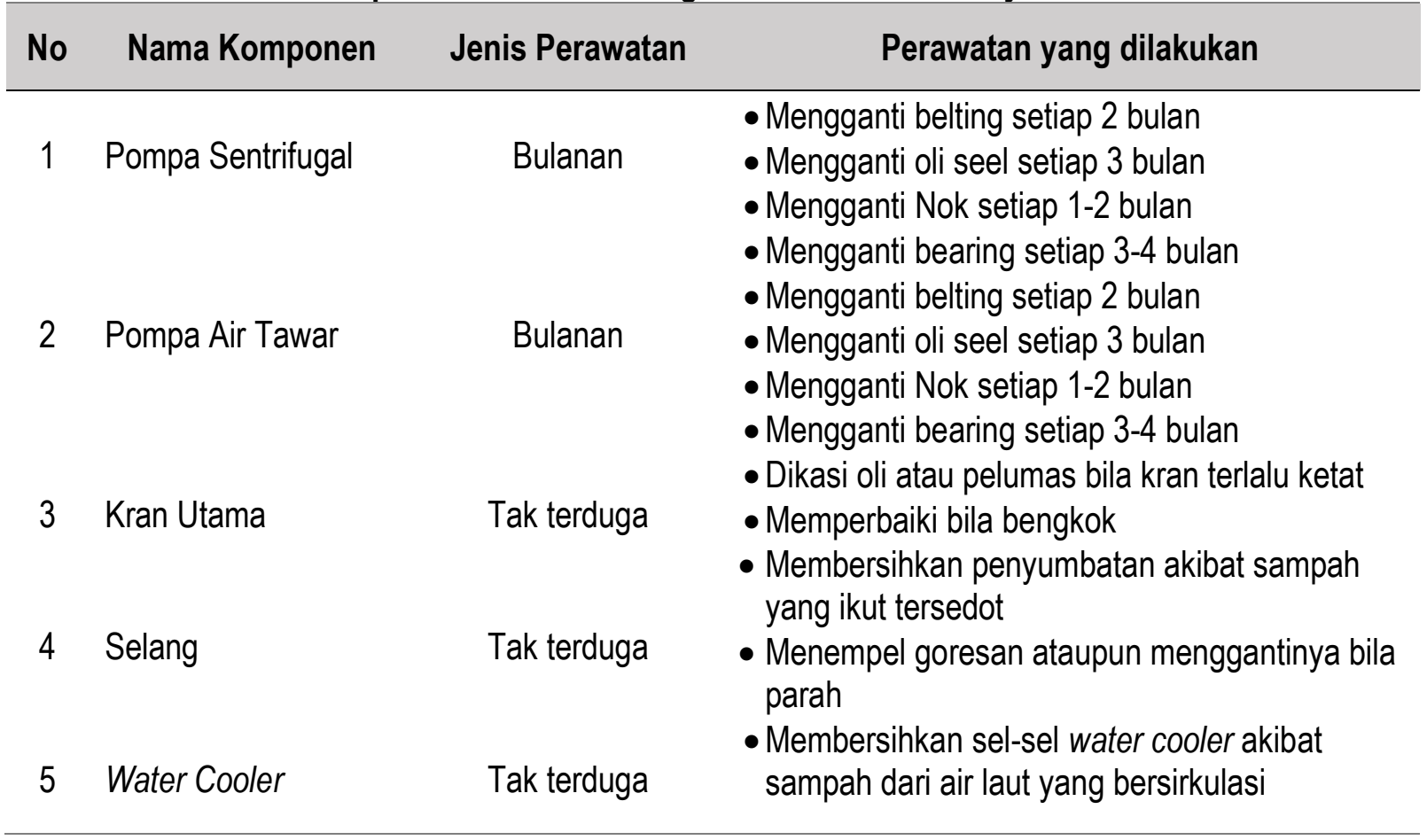

Pada sistem pendingin KM .Sido Mulyo Santoso menggunakan sistem pendingin secara tidak langsung, oleh sebab itu perlu diperhatikan kekurangan atau kehilangan air yang disebabkan oleh beberapa faktor seperti kebocoran dan penguapan. Selain itu selain memperhatikan hal tersebut perawatan terhadap komponen-komponen sistem pendingin harus memperhatikan korosi yang disebabkan oleh air laut, oleh karena itu diperlukannya bahan pelindung korosi. Untuk dapat memahami bagaimana perawatan sistem pendingin pada kapal KM. Sido Mulyo Santoso, dapat dilihat pada Tabel 3. 


\section{Kesimpulan}

Prinsip kerja sistem pendingin pada kapal KM. Sido Mulyo Santoso yaitu menggunakan sistem pendingin tidak langsung, dimana air laut dihisap oleh Pompa Sentrifugal yang kemudian air laut tersebut dialirkan ke dalam komponen water cooler, yang mana di dalam komponen cooler tersebut terdapat air tawar, kemudian air tawar tersebut didinginkan oleh air laut. Sistem pendingin adalah salah satu sistem yang sangat berperan penting dalam menunjang kinerja mesin induk, sistem pendingin berfungsi sebagai penukar kalor supaya suhu pada mesin induk dapat bekerja dengan baik dan tetap pada temperatur normal.

\section{Daftar Pustaka}

Budiman, A., Syarief, A., \& Isworo, H. (2014). Analisis Perpindahan Panas dan Efisiensi Efektif High Pressure Heater (HPH) di PLTU Asam-Asam. Jurnal IImiah Teknik Mesin Unlam, 3(2), 76-82.

Darma, N. M., Supomo, H., \& Nugroho, S. (2010). Analisa Kondisi Mesin Induk Kapal Dengan Aplikasi. $1-12$.

Djeli, M. Y., \& Saidah, A. (2016). Pengaruh Temperatur Pendingin Mesin terhadap Kinerja Mesin Induk di KM TRIAKSA. Seminar Nasional TEKNOKA, 194-198.

Julianto, T., Kusuma, I. R., \& Prananda, J. (2016). Pemanfaatan Perbedaan Temperatur pada Main Engine Cooling System sebagai Energi Alternatif untuk Pembangkit Listrik di Kapal. Jurnal Teknik ITS, 5(2), 0-4.

Legiman, \& Sulaiman, F. (2014). Perawatan Dan Perbaikan Sistem Pendingin Mesin Mitsubishi Galant 2500 Cc. Jurnal Teknovasi, 1(1), 26-34.

Sudrajat, J. (2017). Analisis Kinerja Heat Exchanger Shell \& Tube pada sistem COG Booster di Integrated Steel Mill Krakatau. Jurnal Teknik Mesin (JTM), 6(3), 174-181.

Yaqin, R. I., Zamri, Z. Z., Siahaan, J. P., Priharanto, Y. E., Alirejo, M. S., \& Umar, M. L. (2020). Pendekatan FMEA dalam Analisa Risiko Perawatan Sistem Bahan Bakar Mesin Induk: Studi Kasus di KM. Sidomulyo. Jurnal Rekayasa Sistem Industri, 9(3), 189-200.

Yaqin, R. I., Ziliwu, B. W., Demeianto, B., Siahaan, J. P., Musa, I., Priharanto, Y. E., Efendi, R., Rozaki, M. A., Hasibuan, N. E., \& Arkham, M. N. (2020). Edukasi Perawatan Motor Diesel Kapal Nelayan Desa Pelintung Kota Dumai. Warta Pengabdian, 14(3), 200. 